Proceedings of XIX International Scientific Conference "New Technologies and Achievements in Metallurgy, Material Engineering, Production Engineering and Physics", Częstochowa, Poland, June 7-8, 2018

\title{
Dissimilar Steel-to-Aluminum Joint Structure Made in Laser Welding Technology
}

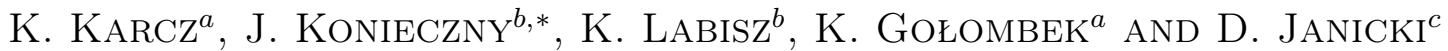 \\ ${ }^{a}$ Silesian University of Technology, Faculty of Mechanical Engineering, \\ Institute of Engineering Materials and Biomaterials, S. Konarskiego 18A, 44-100 Gliwice, Poland \\ ${ }^{b}$ Silesian University of Technology, Faculty of Transport, Department of Railway Transport, Katowice, Poland \\ ${ }^{c}$ Silesian University of Technology, Faculty of Mechanical Engineering, Department of Welding, Gliwice, Poland
}

Currently, the design of the car seat is made of steel, and the automotive industry itself seeks to reduce the weight of vehicles, especially passenger cars, as much as possible. Hence the concept of using aluminium alloys to create a modern skeleton structure of car seats, which would affect the minimization of the weight of the whole car. Laser welding was used due to high technological efficiency and maximum automation of the operation of this process, which determines the repeatability of making welded joints in a very short time. The paper analyses the choice of laser welding parameters of D04 steel with EN AW-6060 aluminium alloy based on the welds obtained. The aim of the structure assessment was to perform macro- and microstructural tests using scanning electron microscopy and microhardness tests of joints at the weld and native materials. The obtained results prove that the weldment of steel from aluminium is a perspective technology that can be used practically in the automotive industry. The goal of the structure analysis was to perform macro- and microstructural investigations using scanning electron microscopy and microhardness testing of weld joints including also the substrate material. Among the tested welding parameters, the most favourable weld parameters values were obtained for: laser power $800 \mathrm{~W}$, weld speed $0.3 \mathrm{~m} / \mathrm{min}$, focus diameter $(\varphi) 200 \mathrm{~mm}$, and beam focus raised by $1 \mathrm{~mm}$ above the surface of the steel plate.

DOI: 10.12693/APhysPolA.135.187

PACS/topics: aluminium alloys, non-alloy steel, laser welding, microstructure

\section{Introduction}

In all modes of transport, a steady mass reduction trend can be observed. This applies to both air transport but also rail vehicles or cars. In the case of passenger cars, a reduction in weight translates into shorter braking distances and, above all, a reduction in fuel consumption [1].

Currently, in most concerns, the construction of the car seat is made of steel, and the automotive industry itself seeks to reduce the mass of vehicles, especially passenger cars, as much as possible. Hence comes the idea of appliance of commonly used aluminium alloys in this area to develop a modern skeleton structure of car seats, which would affect the minimization of the weight of the whole car. In turn, the technology currently used in the industry for the construction of car seats is the laser welding of the car seat mechanism [2,3]. Therefore, a laser welding technology was used to connect a lightweight aluminium alloy with steel to design and fabricate the car seat frame structure. Achieving a permanent combination of these two materials will result in a reduction in the weight of the front and rear seats by as much as $50 \%$, and thus a reduction in the weight of the entire vehicle. Laser welding was also used due to high technological

*corresponding author; e-mail: jaroslaw.konieczny@polsl.pl efficiency and maximum automation of the operation of this process, which determines the repeatability of making welded joints in a very short time.

The aim of the work was to develop laser welding parameters enabling obtaining a permanent connection of non-identical materials: aluminium alloy EN AW6060 and low-alloy steel (low-carbon) for plastic forming DC04.

\section{Materials and investigations methodology}

The following construction materials were used for testing using laser welding process:

- Aluminium alloy EN AW-6060, according to [4];

- Low carbon (low alloy) for plastic deformation DC04, according to standard [5].

The chemical composition of the aluminium alloy is shown in Table I, while the chemical composition of the steel DC04 - in Table II.

Laser welding tests were carried out on $1.2 \mathrm{~mm}$ thick DC04 steel plates and $2.0 \mathrm{~mm}$ thick EN AW-6060 aluminium alloy plate-shape samples. An overlap joint with a single remelting was applied, suitable for this process according to the Polish standard [6].

Laser welding tests were carried out on a research stand at the Faculty of Mechanical Engineering of the Silesian University of Technology in Gliwice. Table III 
TABLE I

Chemical composition of the aluminium alloy EN AW6060 [4].

\begin{tabular}{c|c|c|c}
\hline \hline \multicolumn{4}{|c}{ Concentration of the elements [\%] } \\
\hline $\mathrm{Si}$ & $\mathrm{Fe}$ & $\mathrm{Cu}$ & $\mathrm{Mn}$ \\
\hline $0.30-0.6$ & $0.10-0.30$ & 0.10 & 0.10 \\
\hline $\mathrm{Mg}$ & $\mathrm{Cr}$ & $\mathrm{Zn}$ & $\mathrm{Ti}$ \\
\hline $0.35-0.6$ & 0.05 & 0.15 & 0.10
\end{tabular}

presents laser welding parameters. During the investigations changes were carried out concerning the laser power, welding speed, diameter and focal height.

Chemical composition of steel DC04 [5].

TABLE II

\begin{tabular}{c|c|c|c}
\hline \hline \multicolumn{4}{c}{ Concentration of the elements [\%] } \\
\hline $\mathrm{C}$ & $\mathrm{Mn}$ & $\mathrm{P}$ & $\mathrm{S}$ \\
\hline $\max 0.08$ & $\max 0.40$ & $\max 0.03$ & $\max 0.03$
\end{tabular}

Parameters used during the laser welding process.

TABLE III

\begin{tabular}{|c|c|c|c|c|}
\hline $\begin{array}{l}\text { Sample } \\
\text { number }\end{array}$ & $\begin{array}{c}\text { Laser power } \\
P[\mathrm{~W}]\end{array}$ & $\begin{array}{c}\text { Weld speed } \\
v[\mathrm{~m} / \mathrm{min}] \\
\end{array}$ & $\begin{array}{c}\text { Focus diameter } \\
\varphi[\mu \mathrm{m}]\end{array}$ & Focus height \\
\hline 1 & 600 & 0.5 & 200 & beam focused $3.2 \mathrm{~mm}$ too low \\
\hline 2 & 600 & 0.5 & 200 & $\begin{array}{l}\text { beam focused on the surface of the steel sample and lowering } \\
\text { the focus beam by } 1 \mathrm{~mm}\end{array}$ \\
\hline 3 & 1000 & 0.5 & 200 & without changes \\
\hline 4 & 1000 & 0.5 & 200 & beam focus raised by $1 \mathrm{~mm}$ above the surface of the steel plate \\
\hline 5 & 800 & 0.5 & 200 & without changes \\
\hline 6 & 800 & 0.4 & 200 & without changes \\
\hline 7 & 800 & 0.3 & 200 & without changes \\
\hline 8 & 1200 & 0.5 & 200 & beam focus raised by $1 \mathrm{~mm}$ above the surface of the steel plate \\
\hline
\end{tabular}

Metallographic examinations were performed using the Observer light microscope Z1m by Carl Zeiss.

Images of the structures of the tested materials were made using the SEM Supra 35 scanning electron microscope from Carl Zeiss, equipped with an X-ray energy dispersion spectrometer supplied by EDAX.

The Vickers hardness testing was performed using the Tohyo Japan FM-ARS 9000 microhardness testing device.

\section{Investigation results}

Figures 1 and 2 show the microstructure images of weld joints, on which the area of substrate materials, weld and transition zones are visible. In the presented images, the characteristic areas were marked with points, which were subjected to detailed analysis using a scanning electron microscope. All tests were done in a bright field mode. Microstructural tests for samples 1 and 2 (Table III) were not carried out due to the lack of a stable joint for the tested materials. On the basis of Table III, it can be observed that in this case only the change of the focal length was made, which in the first and in the second attempt to join the materials did not lead to en establishment of a stable joint or connection. In this case, no tests were performed on the scanning electron microscope, analysis of the chemical composition of EDS and the measurement of microhardness.

Only the change of the laser power from $600 \mathrm{~W}$ to $1000 \mathrm{~W}$ in the third test attempt allowed to obtain a permanent connection of the aluminum alloy with steel (Fig. 1).

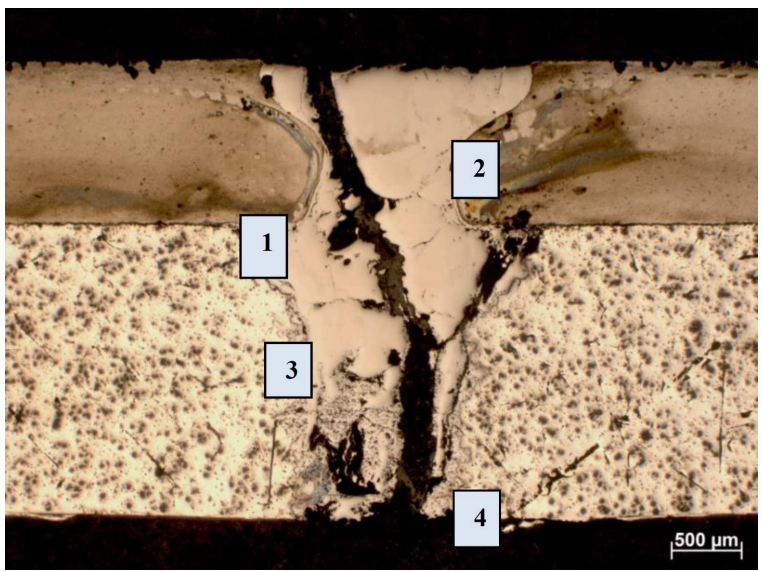

Fig. 1. Sample 3: microstructure image of the joint LM.

Images $1 \div 4$ (Fig. 3) show microstructures from the weld boundary shown in Fig. 1 .

Images $5 \div 8$ (Fig. 4) show microstructures from the weld boundary shown in Fig. 2.

Below are presented the results of metallographic investigations, hardness measurement results and results from the EDS analysis of the chemical composition of different aluminum alloy EN AW6060 and the DC04 steel treated using laser welding.

In the first stage, tests were performed using a quadrant backscattered electron detector (QBSD), as well as an EDS analysis of the chemical composition was carried 


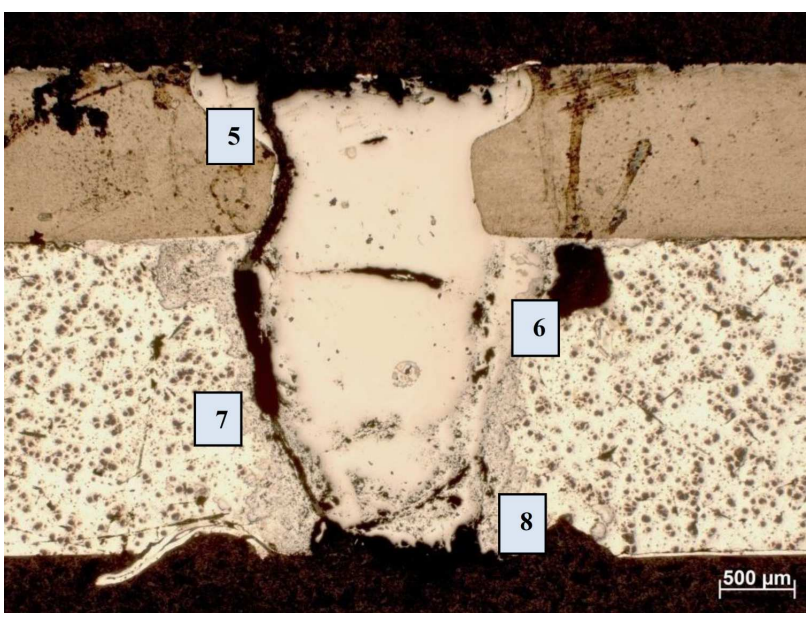

Fig. 2. Sample 7: microstructure image of the joint LM.
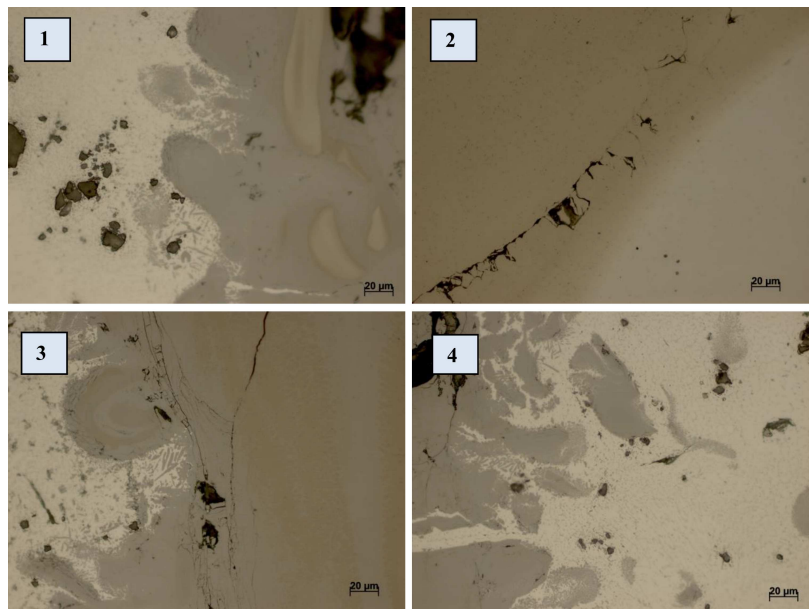

Fig. 3. Microstructure from characteristic areas marked with numbers $1 \div 4$ in Fig. 1 from the edge of the weld, SEM.
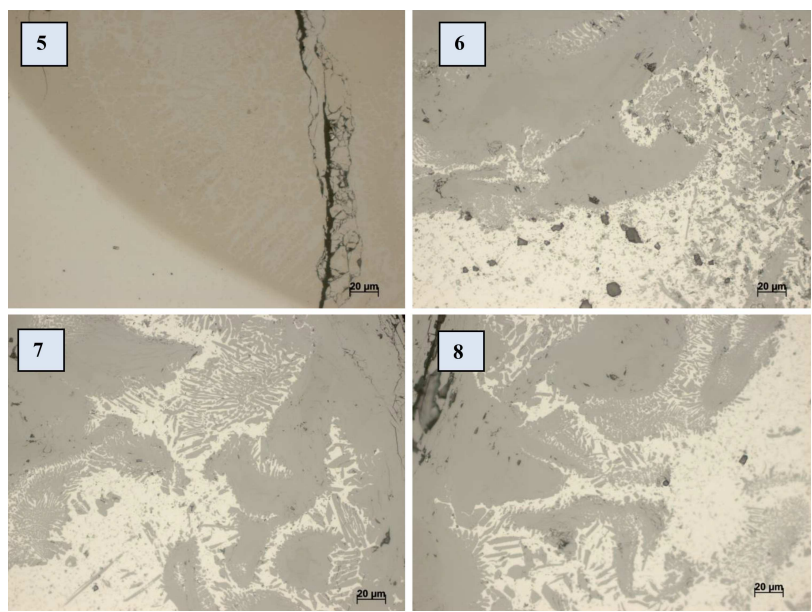

Fig. 4. Microstructure from characteristic areas marked with numbers $5 \div 8$ in Fig. 2 from the edge of the weld, SEM. out. To illustrate the characteristic areas of the samples (Fig. 1 and Fig. 2), the tested areas were presented at different magnifications (Fig. 6 and 7). Additionally for sample no. 7 a linear EDS analysis (Fig. 5) of the chemical composition was performed.

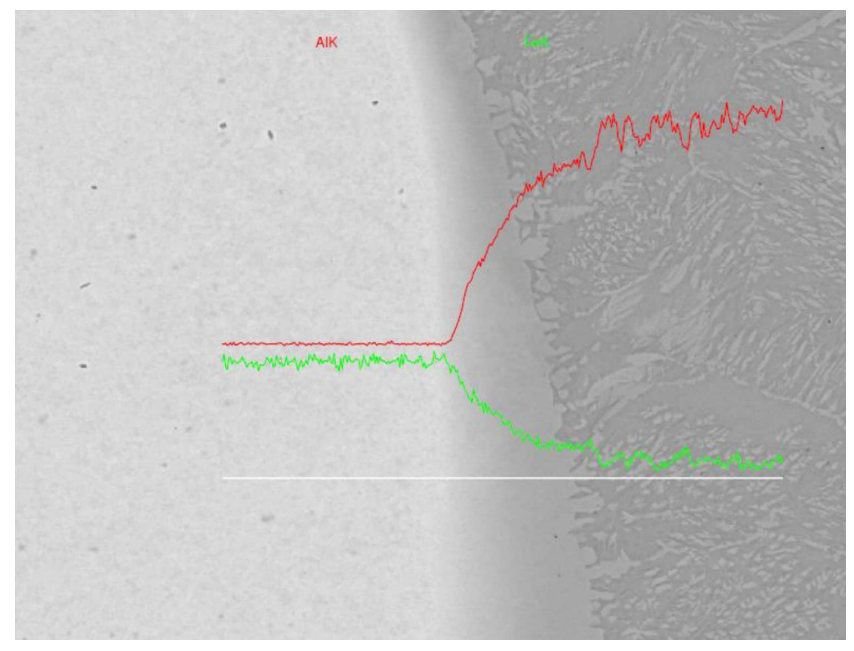

Fig. 5. EDS line analysis of the chemical composition, SEM, $20 \mathrm{kV}, 2000 \times$, sample 7 .

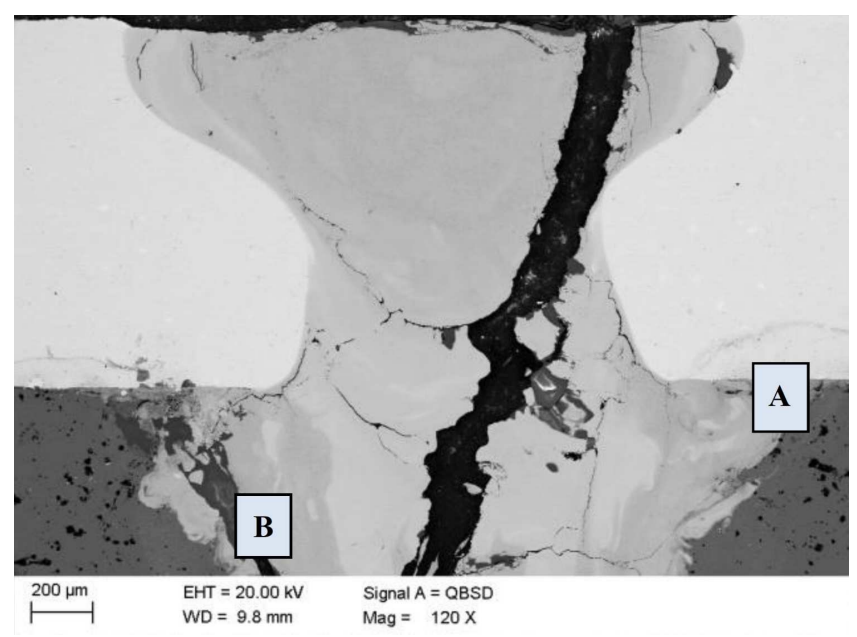

Fig. 6. Image of the top area of the weld, sample 3, SEM.

In Fig. 8 there is presented the area of the upper middle part of the weld. The EDS analysis of the chemical composition shows that in the upper part of the weld, in the middle zone there occurs aluminium, iron, and small amounts of silicon (Fig. 8b). However, in the lower part of the weld at the level of the matrix material aluminium alloy EN AW-6060, only aluminium and iron were found, with a varying percentage depending on the point of measurement (Fig. 8c and d).

In turn, Fig. 9a shows the upper area of the weld at the height of the DC04 steel matrix, as well as the boundary area of the weld between aluminium and steel. Numerous 

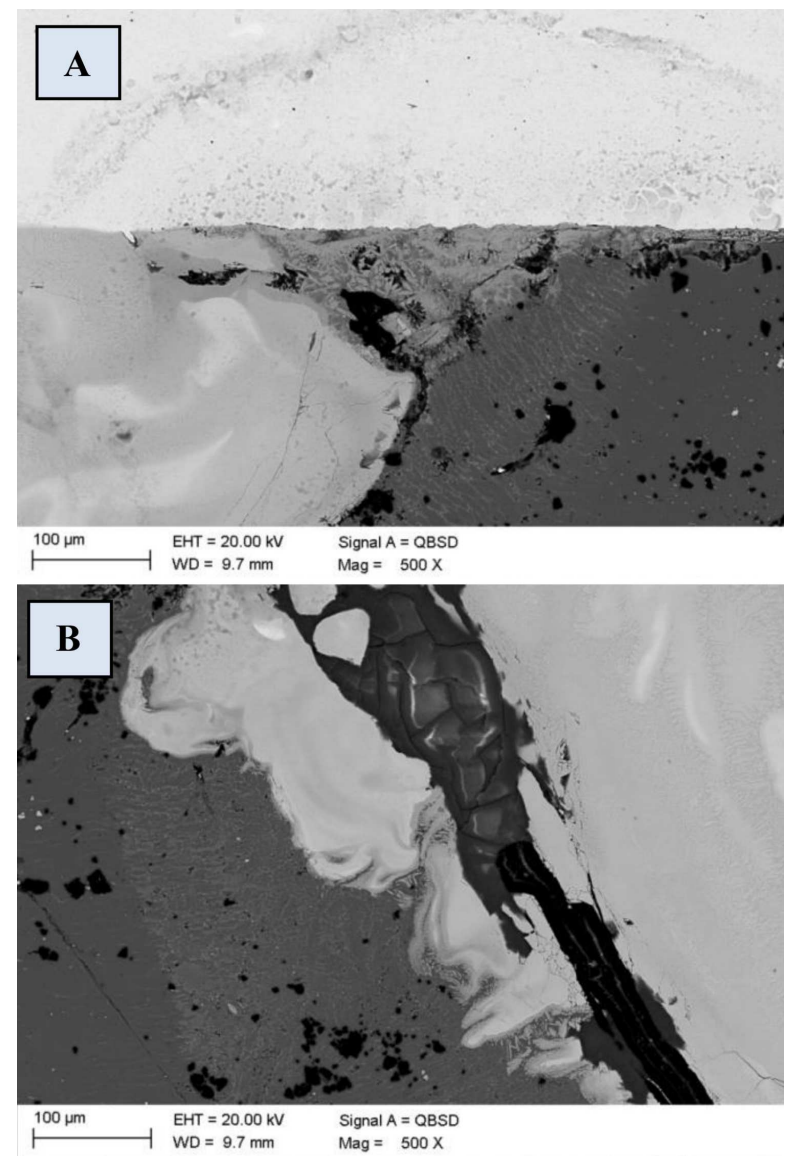

Fig. 7. Microstructure from the characteristic areas in Fig. 6: (A) joining area of the DC04 steel with the EN AW-6060 aluminium alloy, showing the phases of diverse materials, (B) characteristic silicon precipitation in the bottom part of the weld.

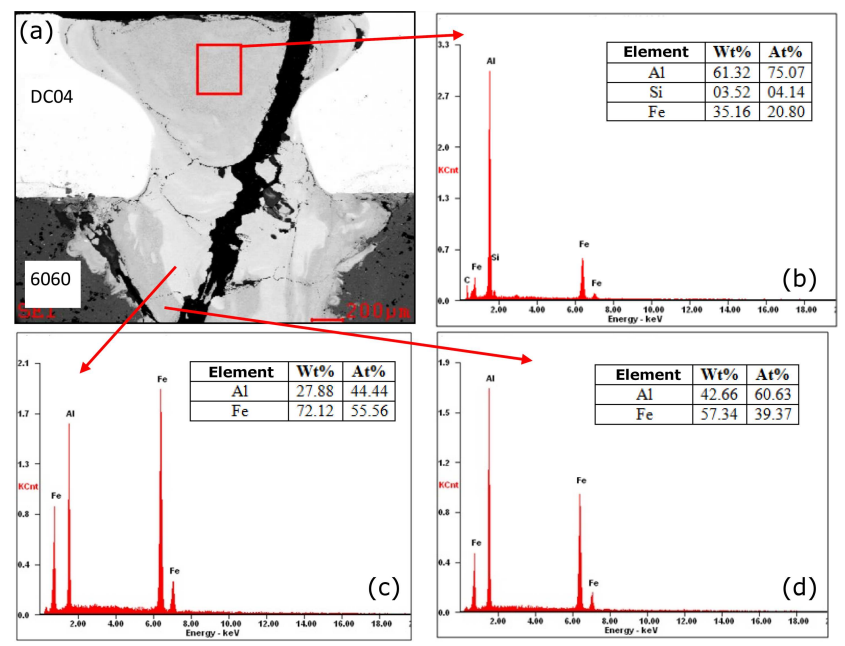

Fig. 8. (a) SEM image of the join weld structure between DC04 steel and EN AW-6060 aluminium alloy and (b)-(d) EDS chemical composition analysis of the darker area, sample 3.

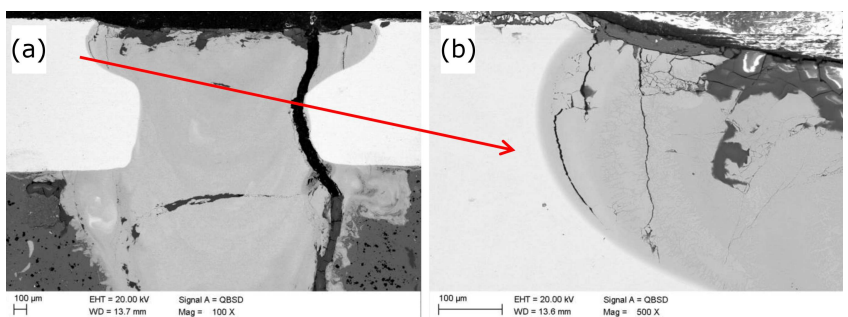

Fig. 9. The image of the upper area of the weld and the magnigfication of the area showing numerous cracks in the weld as well as silicon precipitations (a), (b) magnification of the area marked in part (a); sample 7, SEM.
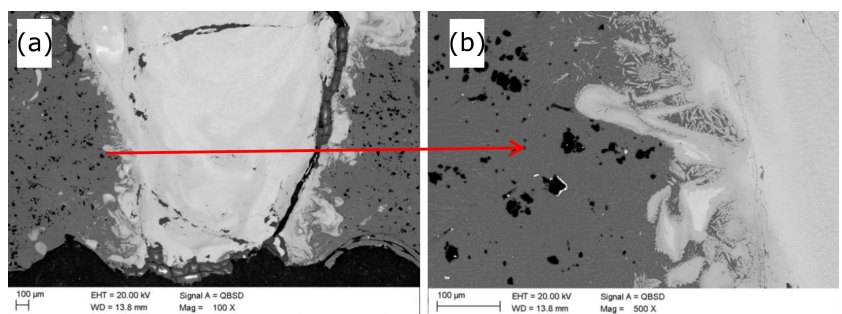

Fig. 10. The image of the lower area of the weld and themagnification ofthe interfacial area, sample 7 (a), (b) magnification of the area marked in part (a); SEM.

transcrystalline cracks in the weld were found as well as silicon precipitation (Fig. 9b). In contrast, Fig. 10a shows the bottom area of the weld at the level of the aluminium matrix (Fig. 10b), revealing especially the weld interface area and the aluminium matrix. In the boundary area there are also visible cracks occurring in the weld, however, they are less and are not as pronounced as in the material on the steel side. What is visible, however, is the penetration of the weld and steel material.
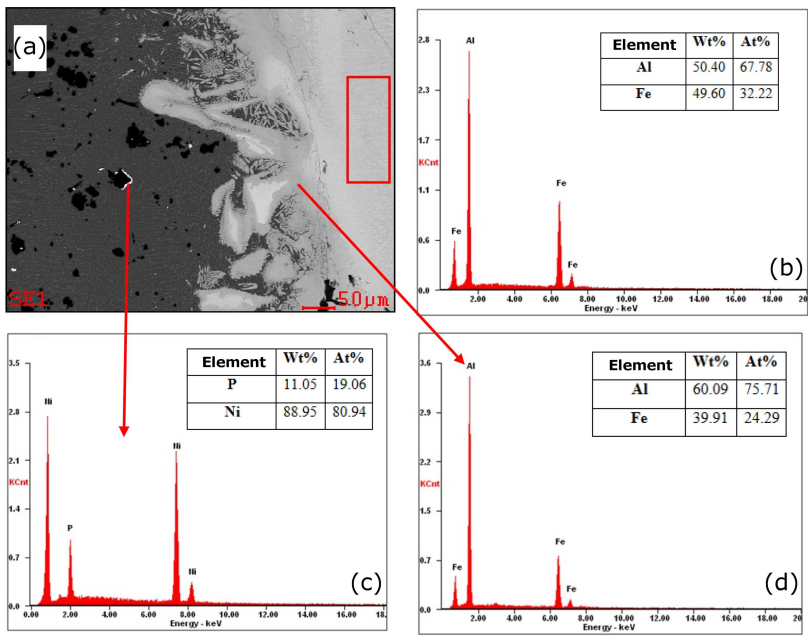

Fig. 11. Microstructure of the weld between DC04 steel and EN AW-6060 aluminium alloy from the weld edge as well as EDS chemical composition microanalysis, sample 7, SEM. (b)-(d) EDS chemical composition analysis from areas marked in part (a), sample 7 . 
Analysis of the chemical composition in the microareas confirmed that the weld formed in the upper part of the joint (steel) is characterized by the smoothness of the transition through the heat affected zone (HAZ), while the weld in the HAZ area of aluminium is not smooth, as a result of remelting with the laser beam there are created also numerous precipitations (Fig. 11).

The next step of the research was a linear analysis of the chemical composition through the matrix material (steel) - HAZ - weld. There is a significant increase in the aluminium content and a decrease in the iron content occurring at the transition point from the parent material (steel) through the HAZ to the weld. In the direction of the weld, the aluminium content increases, while the iron decreases (Fig. 5).

For all samples, EDS analysis of the chemical composition has confirmed the occurrence of silicon in the heat affected zone. This element does not occur in the matrix and does not dissolve in aluminium. So its presence results from its occurrence in the chemical composition of the aluminium alloy EN AW-6060 (Table I). It usually occurs in the form of needles - precipitates of pure silicon. The presence of oxygen is due to its high affinity for aluminium, and it may also be in the form of silicon oxide (which is present). The appearance of carbon in the analysis of the chemical composition of EDS results from the very nature of sample preparation. Carbon and oxygen may also come from including, which would explain their presence in the EDS diagram [7].

For all tests, there occur only single cracks in the HAZ and cracks resulting from non-metallic inclusions occurring on the edge of the weld.

\section{TABLE IV}

A comparison of mean values and standard deviation from microhardness measurements of the welds.

\begin{tabular}{l|c|c|c|c}
\hline \hline Investigated area & Weld & Steel & Aluminium \\
\hline method & HV & HRC & HV & HV \\
\hline \multicolumn{5}{c}{ Sample 3} \\
\hline average & 537.04 & 50.31 & 98.38 & 76.66 \\
standard deviation & 127.82 & 8.32 & 2.5 & 4.64 \\
\hline \multicolumn{5}{c}{ Sample 4} \\
\hline average & 719.43 & 60.84 & 104.20 & 64.07 \\
standard deviation & 52.84 & 2.24 & 3.09 & 6.47 \\
\hline \multicolumn{5}{c}{ Sample 6} \\
\hline average & 738.88 & 61.65 & 107.14 & 64.82 \\
standard deviation & 44.75 & 1.82 & 11.95 & 4.62 \\
\hline \multicolumn{5}{c}{ Sample 7} \\
\hline average & 780.73 & 63.20 & 111.35 & 65.01 \\
standard deviation & 51.12 & 1.84 & 10.65 & 6.03
\end{tabular}

In the next step of the research, microhardness measurements of the obtained welds, HAZ, and parent materials were made. 10 measurements were taken for each of the samples. In the case of a weld, the measurement for all samples was made take from the upper to the bottom of the weld. In the case of DC04 steel and aluminium alloy, equally for all cases the measurements were performed equally from the parent material to the weld. The arithmetic mean and standard deviation were calculated from the obtained results. The results obtained for each of the samples are shown in Table IV. In the case of weld measurement, the HV value was converted to HRC. Differences in the weld hardness result among others from differences in the chemical composition between the samples (compare Fig. 8 and Fig. 11). These differences result from the use of various laser welding parameters. Differences in the hardness of the welds obtained are the result, inter alia of differences in the chemical composition of the welds of the samples tested (see Fig. 8 and Fig. 11). These differences are a result from the use of various laser welding parameters.

The average value of microhardness for aluminium is about $67 \mathrm{HV}$, while for steel it is classified at $105 \mathrm{HV}$. On the basis of Table IV, it can be seen that microhardness for sample 7 is higher by about $13 \mathrm{HRC}$ than for sample 3. This may result not only from the quality of the weld but also from the selection of appropriate parameters of the laser welding process for sample 7 . This weld is characterized by the highest microhardness value and the best quality of the joint with a single crack on the left side along the weld.

In the last stage of the research, the width of the weld was measured using secondary electrons as a processing signal. The measurement results are presented in Table V.

\section{TABLE V}

Thickness measurement results of the weld in the upper area.

\begin{tabular}{c|c}
\hline \hline Sample & $\begin{array}{c}\text { Width of } \\
\text { the cursor }[\mathrm{mm}]\end{array}$ \\
\hline 3 & 2.02 \\
4 & 1.96 \\
5 & 1.83 \\
6 & 2.10 \\
7 & 2.31
\end{tabular}

Based on the results of the weld width measurement, it was found that sample 7 reveals the highest weld width value in its upper part of $2.31 \mathrm{~mm}$, the lowest value was obtained for sample 5, equal to $1.83 \mathrm{~mm}$.

The only possible limitation is metallurgical reactions, which may result in the formation of brittle phases or intermetallic compounds in the weld area, causing the joints to deteriorate or crush [8]. Based on the results of the analysis presented in Figs. 9 and 10, it can be concluded that during the laser welding process depending on the aluminum content in the weld pool, one of the phases of the $\mathrm{Fe}_{x} \mathrm{Al}_{y}$ system was created $\left(\mathrm{Fe}_{3} \mathrm{Al}, \mathrm{FeAl}\right.$, $\mathrm{FeAl}_{3}$ or/and $\mathrm{Fe}_{2} \mathrm{Al}_{5}$ ), which adversely affects strength and plastic properties $[9,10]$.

Hot cracks are not currently common phenomena during welding. However, they appear 
during welding of non-alloy steels of common quality, in which there are relatively more $\mathrm{S}, \mathrm{P}$, and $\mathrm{C}$ [11].

The EDS analysis of the chemical composition confirmed the occurrence of mainly $\mathrm{P}$ and $\mathrm{C}$, so the crack generated in the laser welding process may be hot cracks, which are visible in Figs. 6 and 9a.

Other types of changes apart from metallurgical processes resulting from welding are the introduction of hydrogen and the presence of small non-metallic inclusions (e.g. porosity, slags in most cases on the edge of the weld), which are the main reason for cracks occurrence. The most common case is the occurrence of a crack starting from the edge of a transverse weld or from the end of a non-continuous longitudinal weld. Characteristic cracks at the edge of the weld usually begin with a geometric weld located on the weld line [12]. Its presence in key construction sites is one of the conditions for brittle fracture. However, a significant number of cracks most often begin in the heat affected zone [13].

The cause of fatigue cracks is usually the so-called an acute defect (gap) that is like a crack and increases under the influence of cyclic loading. The most dangerous stress concentrators for the entire structure are sticking, flooding and tearing at the edge of the weld face. During the tests on the light microscope most probably a picture of characteristic flooding was obtained. However, in contrast to the classical flooding located at the edge of the weld, in the case of laser welding, floods near the root of the weld were obtained.

Perhaps the quality of the weld is also influenced by the location of the focus beam, which determines the shape of the weld obtained. Based on the weld width and the corresponding changes in the beam focus placement (Table III), it can be concluded that this relationship is confirmed during the investigation results analysis.

\section{Conclusions}

Achieving a permanent connection of the materials tested in the work with reference to the design of car seat skeleton construction would have a positive impact on the reduction of the vehicle's own weight. The possibility of using laser welding (in which the stations are usually equipped in the automotive industry) for joining different materials, requires as an important factor to choose the proper materials allowing stable and durable joining.

The choice of laser welding process parameters has allow to obtain a permanent joining of diverse materials like the EN AW-6060 aluminium alloy and DC04 steel, which is free from defects (Fig. 12). It should be noted, however, that the total absence of defects is not always a necessary for ensuring the quality of the final product. A defect is considered to be significant when it constitutes a significant obstacle to the requirements of the design project. In the case of welding defects, a possible brittle failure which occurred in the case of sample 5 (laser power
$P=800 \mathrm{~W}$, weld speed $v=0.5 \mathrm{~m} / \mathrm{min}$ ) is not accepted. Total absence of remelting is classified as a surface or internal defect, this case has occurred for samples 1,2

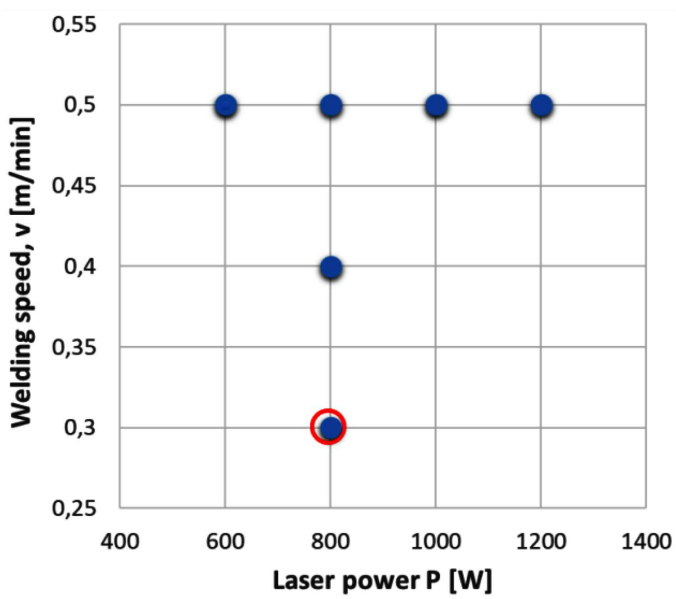

Fig. 12. Scheme of laser welding parameters of the tested materials, optimal weld parameters are marked in red.

(laser power $P=600 \mathrm{~W}$, weld speed $v=0.5 \mathrm{~m} / \mathrm{min}$ ) and 8 (laser power $P=1200 \mathrm{~W}$, weld speed $v=0.5 \mathrm{~m} / \mathrm{min}$ ). For all cases of the tested connections, a parallel crack has occurred in the welds direction in the heat affected zone, which are bed for the construction stability.

\section{References}

[1] P. Snopinski, T. Tanski, K. Labisz, S. Rusz, P. Jonsta, M. Krol, Int. J. Mater. Res. 107, 637 (2016).

[2] P. Kah, J. Lu, J. Martikainen, R. Suoranta, Engineering 5, 700 (2013).

[3] G. Verhaeghe, Industr. Laser Solut. 27, 6 (2012).

[4] PN-EN 573-3:2009. Aluminum and aluminum alloys. Chemical composition and types of plastically processed products. Part 3: Chemical composition and types of products.

[5] PN-EN 10130:2009. Cold-rolled flat products made of low-carbon steels for cold forming. Technical delivery conditions.

[6] PN-EN ISO 6947:1999. Welding and related processes — Welding positions.

[7] D.E. Newbury, N.W.M. Ritchie, J. Mater. Sci. 50 , 493 (2015).

[8] R. Lahdo, A. Springer, R. Pfeifer, S. Kaierle, L. Overmayer, Phys. Proced. 83, 396 (2016).

[9] S. Meco, G. Pardal, S. Ganguly, R.M. Miranda, L. Quintino, S. Williams, Int. J. Adv. Manufact. Technol. 6, 647 (2013).

[10] K.-J. Lee, S. Kumai, T. Arai, Mater. Trans. 46, 1847 (2005).

[11] V. Shankar, J.H. Devletian, Sci. Technol. Weld. Join. 10, 236 (2013).

[12] M.J. Torkamany, S. Tahamtan, J. Sabbaghzadeh, Mater. Des. 31, 458 (2010).

[13] W. Wang, X. Wang, W. Zhong, L. Hu, P. Hu, Proced. Mater. Sci. 3, 1706 (2014). 